\title{
The Larval Stage of Taenia taeniaeformis in Wistar Albino Rats with an Illustration of Biochemical and Histopathological Changes
}

S. Shivaraju, Swapan Kumar Maiti, Divya Mohan, E. Kalaiselvan,

S.P. Sunil Kumar ${ }^{1}$, S. Amitha Banu, Naveen Kumar

10.18805/IJAR.B-4728

\begin{abstract}
Background: Performing all the diagnostic tools before subjecting animals for designed experimental study is time consuming and economically not feasible. Furthermore, it may divert the researchers from original planned work to other areas. But these factors not acceptable to compromise in the assessment of effect of different regenerative agents, drugs and herbal preparation on liver. This is important to prevent any diversions in the actual results of the research due to the prior infection caused by Strobilocercus fasciolaris the lab animals. The study aimed to detect Strobilocercus fasciolaris infected Wistar albino rats using biochemical parameters as a diagnostic marker before subjecting the animals to any designed experimental study.

Methods: The study mainly utilizes abdominal exploration, morphological examination of the larvae, histopathological examination of liver and finally the biochemical parameters changes in the concerned animal. 192 animals used for this study in that 32 had single to multiple cysts in the liver on abdominal exploration. Characteristic Strobilocercus larval morphology, histopathological alterations on liver and serological biomarkers was studied.

Result: Our results showed that the serum levels of alanine aminotransferase, aspartate aminotransferase, alkaline phosphatase, glucose, gamma glutamyl transferase, blood urea nitrogen, and total protein can be used as indicators to measure the severity of Strobilocercus fasciolaris larva infection in rats.
\end{abstract}

Key words: Biochemical, Diagnostic marker, Histology, Strobilocercus fasciolaris, Wistar rats.

\section{INTRODUCTION}

Rat and mice animal models are the most commonly used for studying the effect of stem cells on liver cirrhosis and partial hepatectomy. The zoonotic diseases like rabies, tetanus, salmonella and rat fever can be spread by laboratory rodents (Medhi and Prakash, 2010). Hence, it is necessary to have knowledge about the zoonotic diseases transmitted by laboratory animals Furthermore, as a researcher should keep in the mind that asymptomatic parasitic diseases of experimental animals may affect the results of experiments (Sengupta et al., 2011). Taenia taeniaeformis is a cestode parasite with cats, dogs and carnivores like stoats and lynx as primary definitive hosts. Rodents (wild and laboratory) and humans are intermediate host and accidental host for this parasite respectively. The larval stage (metacestode) develops in the liver parenchyma of the intermediate host (rodents) (Soulsby, 2005). This metacestode called with various names; bladder worm, Hydatigera fasciolaris, Strobilocercus fasciolaris, Cysticercus fasciolaris and Taenia crassicolis (Al-nazzar, 2009; Karim, 2010). Although this parasite is cosmopolitan in distribution in wild rats ( $Y i$ et al., 2014; Panti-May et al., 2015) but its occurrence in laboratory animals is rare (Singla et al., 2008; Moudgil et al., 2016; Krishnamoorthy et al., 2017). The infected rodents are usually asymptomatic subclinical with rare complications like abdominal enlargement (Soulsby, 2005). The diagnosis in cats (direct host) is by observation of proglottids or identification of taeniid eggs in feces by flotation or
Division of Surgery, ICAR-Indian Veterinary Research Institute, Izatnagar-243 122, Uttar Pradesh, India.

'Division of Veterinary Extension Education, ICAR-Indian Veterinary Research Institute, Izatnagar-243 122, Uttar Pradesh, India.

Corresponding Author: S. Shivaraju, Division of Surgery, ICARIndian Veterinary Research Institute, Izatnagar-243 122, Uttar Pradesh, India. Email: shivaraju558@gmail.com

How to cite this article: Shivaraju, S., Maiti, S.K., Mohan, D., Kalaiselvan, E., Kumar, S.P.S., Banu, S.A. and Kumar, N. (2021). The Larval Stage of Taenia taeniaeformis in Wistar Albino Rats with an Illustration of Biochemical and Histopathological Changes. Indian Journal of Animal Research. DOI: 10.18805/IJAR.B-4728.

Submitted: 17-07-2021 Accepted: 06-10-2021 Online: 03-11-2021

sedimentation. Whereas, in rodents (intermediate host) is based on demonstrating the metacestode stages in the liver.

In experimental conditions hepatic cyst/tumor in laboratory animals can be diagnosed by ultrasonography, radiography, serological examination and molecular procedures like PCR-linked mitochondrial DNA sequencing (Sengupta, et al., 2011). Performing all the diagnostic tools before subjecting animals for designed experimental study is time consuming and economically not feasible. Furthermore, it may divert the researchers from original planned work to other areas. But these factors not acceptable to compromise in the assessment of effect of different regenerative agents, drugs and herbal preparation 
on liver. In this study, we hypostasized that infection caused due to Strobilocercus fasciolaris in liver of laboratory Wistar albino rats may show some changes in the serological/ biochemical parameters that may help in selection of laboratory animal before preparing the liver cirrhosis/ partial hepatectomy animal models. As far as authors are aware, there is no published report of serological/biochemical changes due to $S$. fasciolaris in Wistar albino rats in incidental findings. Therefore, the main objective of this study was efficient diagnosis based on serology, morphology and histopathological study of Wistar albino rats liver affected with Strobilocercus fasciolaris.

\section{MATERIALS AND METHODS}

In our setting, we conducted experiments involving Wistar albino rats, maintained according to the Committee for the Purpose of Control and Supervision on Experiments on Animals (CPCSEA) guidelines to study the hepatoprotective/ regenerating effect of stem cells on rat liver after preparing liver cirrhosis and 70\% partial hepatectomy models.

\section{Study animals}

One hundred nighty two (192) Wistar albino rats of either sex were used for preparation of animal model of partial hepatectomy. All the animals were procured from Laboratory Animal Resource section, ICAR-IVRI, Izatnagar and were allowed for 15 days to get acclimatized to the new environment. All the animals received standard diet and ad libitum water.

After collection of $2 \mathrm{ml}$ of blood for serum from orbital plexus, all rats were anaesthetized with midazolam/ ketamine. Ventral abdomen region was prepared aseptically. A midline incision was made and cranial abdomen was exposed. The liver was exteriorized. Animals showed single/ multiple cysts on liver was excluded from the routine study (i.e. hepatectomy model) and included in the present study (Group A, N=32) (Plate 1c). The 35 normal animals were randomly selected from routine study (Group $B, N=35$ ) for comparison of serological parameters. The animal had normal liver had undergone $70 \%$ hepatectomy surgery (Plate 1d), whereas animals with liver cyst were euthanized.

\section{Exploration of abdominal cavity}

In group A, animals after euthanizing, visceral organs were examined thoroughly for the presence of cysts or any abnormalities. The location, number and size of the cysts in the liver were recorded.

\section{Grenacher's borax carmine for staining tapeworm larva}

The morphological features of larva studied as per method described by Meyer and Oslen, (1975); Moudgil et al. (2016).

\section{Histopathological examination}

The liver samples were collected from all the animals and stored in $10 \%$ neutral buffered formalin. Sections of $5 \mu \mathrm{m}$ were prepared and stained with haematoxylin and eosin stain.

\section{Serological examination}

Concentration of the serum components was measured on alanine aminotransferase (ALT), aspartate aminotransferase (AST), alkaline phosphatase (ALP), blood urea nitrogen (BUN), total bilirubin (TB), gamma glutamyl transferase (GGT) and total protein (TP) using commercial available kits (Coral diagnostic Ltd). Blood glucose (Glu) was estimated in the blood using glucometer (On-Call-Plus ${ }^{\circledR}$ ).

\section{Statistical analysis}

The data were analyzed by using the Statistical Program for Social Sciences (SPSS 20 IBM). Independent t-test was performed for comparing the mean values between the groups. A value of $\mathrm{P}<0.05\left(^{*}\right)$ was considered to be statistically significant and $P<0.01\left(^{* *}\right)$ was considered to be statistically highly significant.

\section{RESULTS AND DISCUSSION Gross pathology findings}

Out of one hundred nighty two (192) Wistar albino rats assigned for rat model of partial hepatectomy, 32 (16.66\%) were infected with cyst. The color of the cyst was ranging from white to cream. The single to multiple cysts with the size varying from $1 \mathrm{~mm}$ to $12 \mathrm{~mm}$ was observed same is represented in Table 1 (Plate 1a). 15 (46.8\%) animals showed hepatic cyst only on medial lobe and $8(25 \%)$
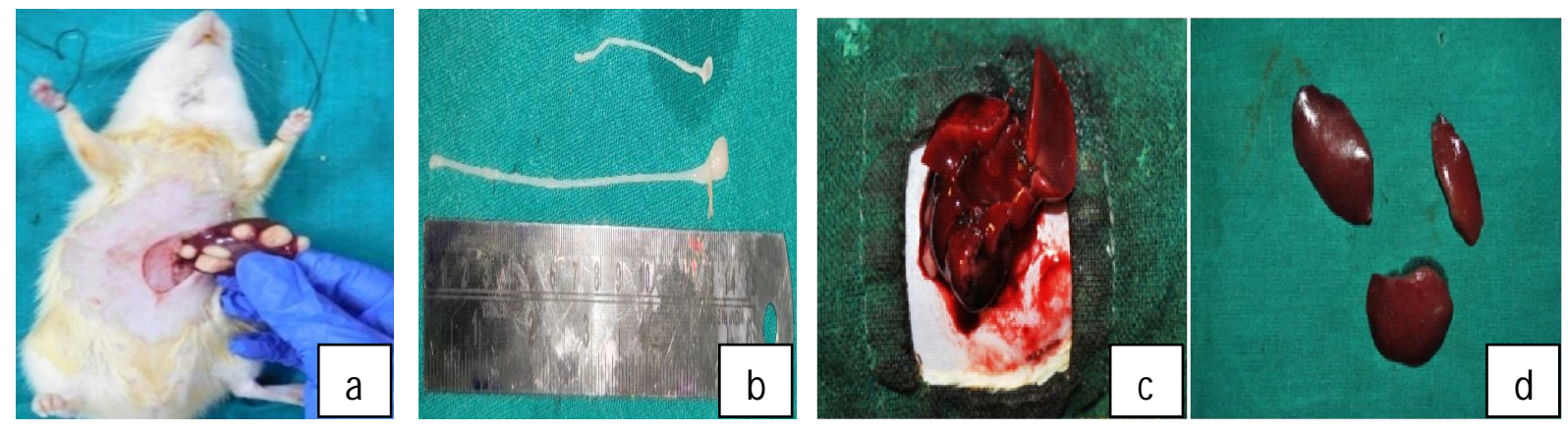

Plate 1: Photograph of animal showing multiple white to creamy colored hepatic cysts (a), gross T. taeniformis (b), 70\% hepatectomy (c) Excised liver mass (d) 
animals had cyst on left lateral lobe. Whereas, cysts on all four lobes of liver were observed in $9(28 \%)$ animals. On examination of the other visceral organs, out of 32 animals only $3(9.3 \%)$ showed tumorus growth on large intestine.

All the rats were apparent healthy and supple. Previous researchers also reported the healthy physical status of rats in spite of presence of $C$. fasciolaris in their liver (Kataranovski et al., 2010; Claveria et al., 2005). This suggested the well-established parasite-host relationship. The infection rate of $C$. fasciolaris in the laboratory rats was $16.6 \%$. The urban cat infected with the $T$. taneiformis may contaminate the bedding material with feces. The infection might be spreaded from one animal to other through the contaminated water, feed or bedding materials (Soulsby, 2005). The possible entry of infection through inter or intra institutional exchange of animals and tape worm egg on shirt of animal care takers and researchers should be taken into account.

Table 1: Description of the number and average size of the cysts observed in the infected rat liver.

\begin{tabular}{lcc}
\hline $\begin{array}{l}\text { Number } \\
\text { of rats }\end{array}$ & $\begin{array}{c}\text { Number of } \\
\text { cysts per liver }\end{array}$ & $\begin{array}{r}\text { Average relative size of cysts } \\
\text { (in mm) (Mean } \pm \text { S.D.) }\end{array}$ \\
\hline 19 & 1 to 5 & Small $(2.76 \pm 1.13)$ \\
11 & 5 to 10 & Medium $(6.85 \pm 1.2)$ \\
02 & $>10$ & Large $(10.5 \pm 0.35)$ \\
Total & 32 & \\
\hline
\end{tabular}

Table 2: Data are expressed as mean \pm SD. Data were analyzed for differences between the 2 groups.

\begin{tabular}{lcc}
\hline Parameters & Group A (Infected) & Group B (Normal) \\
\hline Blood glucose & $46.34 \pm 14.06$ & $141.34 \pm 39.267^{* *}$ \\
AST & $178.34 \pm 27.99$ & $100.0 \pm 4.017^{* *}$ \\
ALP & $241.84 \pm 64.85$ & $136.98 \pm 56.63^{* *}$ \\
GGT & $4.39 \pm 2.23$ & $2.11 \pm 2.23^{* *}$ \\
ALT & $73.8 \pm 11.74$ & $54.15 \pm 2.1^{* *}$ \\
B UN & $34.68 \pm 3.436$ & $34.9421 \pm 2.985$ \\
Total protein (TP) & $5.483 \pm 1.203$ & $6.112 \pm 0.719$ \\
Total bilirubin (TB) & $0.327 \pm 0.394$ & $0.154 \pm 0.30^{* *}$ \\
\hline
\end{tabular}

\section{The identification of larva}

Each cyst contained a single, live, characteristic Strobilocercus larva. The larvae measured 10 to $17 \mathrm{~cm}$ in length and 1 to $2 \mathrm{~mm}$ in diameter (Plate $1 \mathrm{~b}$ ). Examination of larvae revealed that they had an elongated neck of about 2 $3 \mathrm{~cm}$ length, a big scolex and pseudo-segmentation of entire body length with terminal bulged portion. Genital organs were not found in the segmented strobila. The larva had an armed rostellum with two rows of typical claw hammer shaped hooks. Based on the morphology and their anatomical site of predilection, the larva was identified as Strobilocercus of Taenia taeniaeformis (Plate $2 \mathrm{a}$ and $2 \mathrm{~b}$ ).

The macroscopically cyst examination revealed, white to cream color as reported by previous authors (Krishnamoorthy et al., 2017; Sharma et al., 2017). The number of cysts directly proportional to the number of eggs ingested (Rodríguez-Vivas et al., 2011; Hasanpour et al., 2017), we observed single to 10 cysts in rat liver. The size of cyst 19 animals showed 1 to $5 \mathrm{~mm}, 11$ animals had 5 to 10 $\mathrm{mm}$ size and remaining animal had size of more than 10 $\mathrm{mm}$. The variation in the size of the liver cyst is depends on the stage larvae development, duration of infection (Sharma et al., 2017). In our study animal showed different ranges of cyst sizes may be due to infection occur at different time interval and this accordance with others reports (Moudgil et al., 2016). The infection is less than 30 days, only small cyst involving the fewer lobes observed. When there is more than 30 days old, infection with number of larger cysts involving the all the liver lobes can be seen (Hanes, 1995). The most commonly affected lobe observed is right medial lobe and it is arguable with findings of Hasanpour et al., (2017) in urban rats, this could be due to increase blood supply to the lobe via portal triad. According to Soulsby, (2005) the larvae of C. fasciolaris can be identified with morphological appearances. The detailed examination of larva may help in diagnosis. The length and diameter of the larva and number of hooks in rostellum all features in this study were consistent with findings of other researchers (Sharma et al., 2017; Hasanpour et al., 2017).

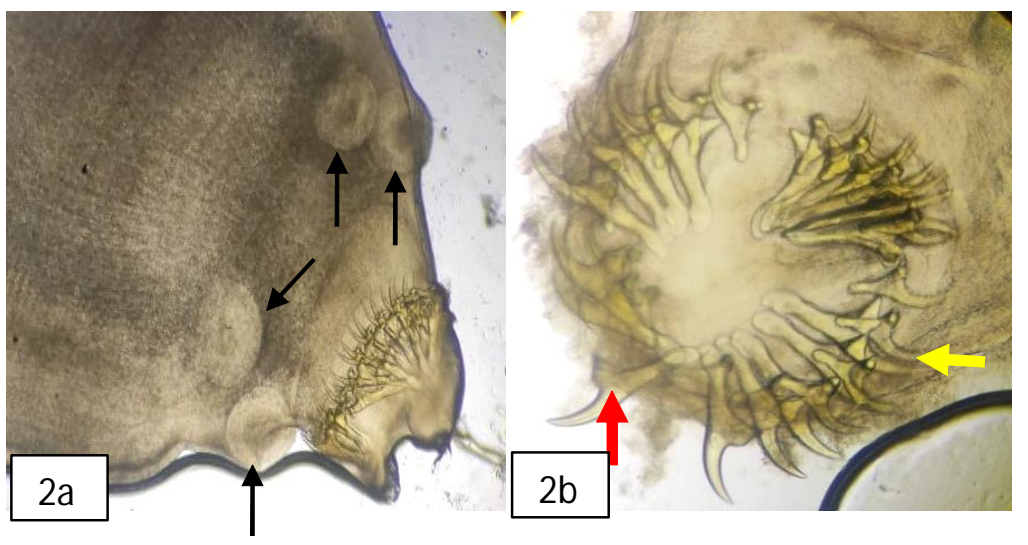

Plate 2: Photograph of Taenia taeniformis larva revealed armed rostellum characterized by two rows of typical claw hammer shaped small hooks (yellow colour arrow) and large hooks (red colour arrow) with four suckers (Black arrows). 


\section{Histopathological examination}

Histopathologically, the larvae of Strobilocercus fasciolaris were encapsulated by a thick fibrous tissue capsule within the liver. The hepatocytes are atrophied due to pressure created by cyst. Fatty degeneration and infiltration of lymphocytes, plasmocytes and eosinophils were evident. The cyst wall composed of two layers, an inner layer made of loose connective tissue with fibrocytes and delicate connective tissue fibers (Plate $3 a$ ). The outer layer was composed of an aggregation of lymphocytes, plasmocytes and a very few eosinophils (Plate $3 b$ ).

Histopathologically, by considering larva as invader liver started defense mechanism, resulted in formed double layer cyst around the parasite larva. Furthermore, infiltration of lymphocytes and eosinophil and absence of macrophages indicate acute infection. Similar studies on hepatic cysts in rat liver shown same results (Al-nazzar, 2009).

\section{Serological examination}

Concentrations of the seven serum components and blood glucose measured are shown in Table 2. The glucose concentration was significantly lower in group A (infected animal) compared to control group. The level of liver function serum biomarkers like ALT, GGT, ALP, AST and total bilirubin were significantly higher in parasite infected animals. The level BUN and total protein didn't show any significant difference between the groups.

The present study analyzed serum concentration of nine parameters in order to use as diagnostic markers/tool. The glucose concentration in the incidental parasite infected rats is lower compared to control group. Whenever glucose available, tapeworm absorb and consume the glucose, interestingly store the excess as glycogen (Roberts, 1983). Same finding was reported by Irizarry-Rovira, 2007 in Taenia taeniaeformis infected in pet rat. The destruction of hepatocytes by $S$. fasciolaris larva might be responsible for the more release of liver enzymes into the blood. The concentration of the enzymes is directly related to the number of cell death and duration of injury.

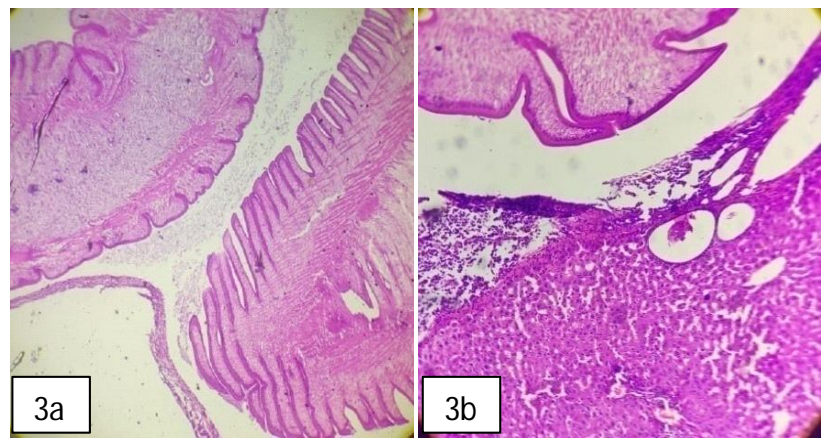

Plate 3: Section of liver of Rattus norvegicus showing intact Cysticercus fasciolaris inside the thick fibrous connective tissue capsule and eosinophilic infiltration around the parasite and atrophied liver cells. Haematoxylin and eosin stain.
In the present study, the AST, ALT, GGT and ALP enzymes concentration is higher. Furthermore, the ALT enzyme shows a higher increase in comparison with AST, it is because of the acuteness of the infection and location of the enzymes in cells. The increased GGT and ALP levels in infected rats are might be due to damage to bile duct by larvae, it is accordance with findings in sheep and cattle during fluke infection (Ferre et al., 1997; Molina et al., 2006; Hasan et al., 2018). Konno et al., 1999 reported that decreased total protein and higher BUN after 56-70 days of post infection. Acute infection of less than 30-45 days may be reason for contrary findings in our study compare to previous researchers. There are no published descriptions of the serological enzymes of those rats infected with Strobilocercus fasciolaris (hepatic cyst) and the present report addressed this gap in the scientific literature. Therefore, present data establish the serum levels of different enzymes, which may be used as indicators of both levels of infection and severity of damage, caused by Strobilocercus fasciolaris and would be one of the main criteria for the selection of experimental animals for liver regenerative study.

\section{Zoonotic importance}

The possibility of zoonotic spread of Taenia taeniaeformis cannot be ignored, as cases were reported from different countries like Sri Lanka, Argentina, Czechoslovakia, Denmark etc. (Perry et al., 1994; Shashi et al., 2013). The awareness about zoonotic importance of different parasitic diseases should be provided to the animal care takers and researchers.

\section{CONCLUSION}

While selecting the Wistar albino rats for studying the regenerative/hepatoprotective effect of different therapies on liver, the serum levels of alanine aminotransferase, aspartate aminotransferase, alkaline phosphatase, glucose, gamma glutamyl transferase, blood urea nitrogen and total protein may be used as indicators of level and severity of the Strobilocercus fasciolaris larva infection.

\section{ACKNOWLEDGEMENT}

Authors are thankful to Director ICAR-IVRI, Izatnagar, Barielly (U.P.), for providing laboratory facilities and encouragement during course of work. Authors are also thankful to Dr Manjunathachar H V, Scientist B, ICMR, for helping in interpretation of morphology of tapeworm larva.

\section{REFERENCES}

Al-najjar, S.S., Kadhim, F.S. and Abdalrziak, N.A. (2009). Parasitological and pathological study of the Cysticercus fasciolaris that are naturally infest white mice. Al-Anbar Journal of Veterinary Sciences. 2: 43-47.

Claveria, F.G., Causapin, J. De Guzman, M.A. Toledo, M.G. and Salibay, C. (2005). Parasite biodiversity in Rattus spp caught in wet markets. Southeast Asian Journal of Tropical Medicine and Public Health. 36: 146-148. 
Ferre, I., Ortega-mora, L. M. and Rojo-vázquez, F. A. (1997). Serum and bile antibody responses (IgG and $\lg A$ ) during subclinical Fasciola hepatica infection in sheep. Veterinary Parasitology. 68(3): 261-7.

Hanes, M.A. (1995). Fibrosarcomas in two rats arising from hepatic cysts of Cysticercus fasciolaris. Veterinary pathology Jul; 32(4): 441.

Hasan, K. M., Tamanna, N. and Haque, M.A. (2018). Biochemical and histopathological profiling of Wistar rat treated with Brassica napus as a supplementary feed. Food Science and Human Wellness. 7(1): 77-82.

Hasanpour, H., Najafi, F., Gharagozlou, M.J., Jafarpour, A.S., Fadavi, A., Paknezhad, N. and Mowlavi, G. (2017). Cysticercus fasciolaris (Taenia taeniaeformis Larval Stage) in urban rats with illustration of histopathological changes in the liver. Journal of Medical Microbiology and Infectious Diseases. 5(3): 43-46.

Irizarry-rovira, A.R., Wolf, A. Bolek, M. (2007). Taenia taeniaeformisinduced metastatic hepatic sarcoma in a pet rat (Rattus norvegicus). Journal of Exotic Pet Medicine. 16(1): 45-8.

Karim, A.J. (2010). Scanning electron microscopy and historical morphology of Cysticercus fasciolaris which induced fibrosarcomas in the Labroratory rat. Annals of Microsocopy. 10: $44-48$.

Kataranovski, M., Zolotarevski, L., Belij, S., Mirkov, I., Stošić, J., Popov, A. and Kataranovski, D. (2010). First record of Calodium hepaticum and Taenia taeniaeformis liver infection in wild Norway rats (Rattus norvegicus) in Serbia. Archives of Biological Sciences. 62: 4314.

Konno, K., Abella, J.A. Oku, Y. Nonaka, N. and Kamiya, M. (1999). Histopathology and physiopathology of gastric mucous hyperplasia in rats heavily infected with Taenia taeniaeformis. Journal of Veterinary Medical Science. 61: 317-24.

Krishnamoorthy, P., Sengupta, P.P. and Balachandran, C. (2017). Cysticercosis in a Wistar Albino Rat. Research and Reviews: Journal of Veterinary Science and Technology. 6: 23-25.

Medhi, B. and Prakash, A. (2010). Introduction to Experimental Pharmacology. Practical Manual of Experimental and Clinical Pharmacology. $1^{\text {st }}$ ed. New Delhi: Jaypee Brothers Medical Publisher (P) Ltd. p. 35.

Meyer, C.M. and Oslen, W.O. (1975). Essentials of Parasitology. W.M.C Brown Company Publishers, Dubuque.

Molina, E.C., Lozano, S.P. and Barraca, A.P. (2006). The relationship between haematological indices, serum gamma-glutamyl transferase and glutamate dehydrogenase, visual hepatic damage and worm burden in cattle infected with Fasciola gigantica. Journal of Helminthology. 80: 277.
Moudgil, A.D., Singla, L.D. Gupta, K., Daundkar, P.S., Vemu, B. (2016) Histopathological and morphological studies on natural Cysticercus fasciolaris infection in liver of Wistar rats. Journal of Parasitic Diseases. 40: 255-8.

Panti-May, J.A. Hernández-Betancourt, S.F. Rodríguez-vivas, R.I. Robles, M.D. (2015). Infection levels of intestinal helminths in two commensal rodent species from rural households in Yucatan, Mexico. Journal of Helminthology. 89: 42.

Perry, R.L., Williams, J.F. Carrig, C.B. Kaneene, J.B. Schillhorn. Van veen, T.W. (1994). Radiologic evaluation of the liver and gastrointestinal tract in rats infected with Taenia taeniaeformis. American Journal of Veterinary Research. 55: $1120-6$.

Roberts, L.S. (1983). Carbohydrate metabolism. In: [Arme, C. and Pappas, P.W. editors]. Biology of the Eucestoda. Vol. 2 ed, London: Academic Press, p.343-390. ISBN: 0120621029.

Rodríguez-vivas, R.I., Panti-may, J.A. Parada-lópez, J. HernándezBetancourt, S.F. Ruiz-Piña, H.A. (2011). The occurrence of the larval cestode Cysticercus fasciolaris in rodent populations from the Cuxtal ecological reserve, Yucatan, Mexico. Journal of Helminthology. 85: 458.

Sengupta, P., Sharma, A. Mazumdar, G. and Tripathi, S. (2011). Asymptomatic cysticercosis in wistar albino rats: A note of caution to all biomedical researchers. Indian Journal of Pharmacology. 43: 222.

Sharma. R., Tiwari, K. Birmingham, K. Armstrong, E. Montanez, A. Guy, R. Sepulveda, Y. Mapp-Alexander, V. Deallie, C. (2017). Cysticercus fasciolaris in brown rats (Rattus norvegicus) in Grenada, West Indies. Journal of Parasitology Research.

Shashi, K. Rashmi, Solanki, K. (2013). Study on Zoonotic Cestodes of commensal rats. Int. J. Cun. Sci. 62-66.

Singla, L.D., Singla, N. Parshad, V.R. Juyal, P.D. Sood, N.K. (2008). Rodents as reservoirs of parasites in India. Integrative Zoology. 3(1): 21-6.

Soulsby, E.J.L. Cestodes (2005). In: Helminths, arthropods and protozoa of domesticated animals, $7^{\text {th }}$ ed, London, Bailliere Tindall, Elsevier, ISBN-10: 0812107802.

Yi-Fan, C., Xu-Heng, N. Hui, H. Shou-Yang, D. Duszynski, D.W. Jiang-Hui, B. (2014). Gastrointestinal parasites of root voles, Microtus oeconomus (Rodentia: Muridae), from Haibei Area, Qinghai Province, China. Comparative Parasitology. 81. 185-90. 